\title{
Current issues in transcatheter aortic valve replacement
}

\author{
Silvia Mas-Peiro ${ }^{1,2}$, Stephan Fichtlscherer ${ }^{1,2}$, Claudia Walther ${ }^{1,2}$, Mariuca Vasa-Nicotera ${ }^{1,2}$ \\ ${ }^{1}$ Department of Cardiology, University Hospital Frankfurt am Main, Frankfurt am Main, Germany; ${ }^{2}$ German Center for Cardiovascular Research, \\ DZHK, Partner Site Rhine-Main, Germany \\ Contributions: (I) Conception and design: All authors; (II) Administrative support: None; (III) Provision of study materials or patients: None; (IV) \\ Collection and assembly of data: None; (V) Data analysis and interpretation: None; (VI) Manuscript writing: All authors; (VII) Final approval of \\ manuscript: All authors. \\ Correspondence to: Mariuca Vasa-Nicotera. Department of Cardiology, University Hospital Frankfurt, Theodor-Stern-Kai 7, 60590 Frankfurt am \\ Main, Germany. Email: mariuca.vasa-nicotera@kgu.de.
}

\begin{abstract}
Aortic stenosis is the most common valvular disease worldwide. With transcatheter aortic valve replacement (TAVR) being increasingly expanded to lower-risk populations, several challenging issues remain to be solved. The present review aims at discussing modern approaches to such issues as well as the current status of TAVR. TAVR has undergone several developments in the recent years: an increased use of transfemoral access, the development of prostheses in order to adapt to challenging anatomies, improved delivery systems with repositioning features, and outer skirts aiming at reducing paravalvular leak. The indication of TAVR is increasingly being expanded to patients with lower surgical risk. The main clinical trials supporting such expansion are reviewed and the latest data on low-risk patients are discussed. A number of challenges need still to be addressed and are also reviewed in this paper: the need for updated international guidelines including the latest evidence; a reduction of main complications such as permanent pacemaker implantation, paravalvular leak, and stroke (and its potential prevention by using anti-embolic protection devices); the appropriate role of TAVR in patients with concomitant cardiac ischemic disease; and durability of bio-prosthetic implanted valves. Finally, the future perspectives for TAVR use and next device developments are discussed.
\end{abstract}

Keywords: Transcatheter aortic valve replacement (TAVR); aortic stenosis; low-risk; complications

Submitted Oct 17, 2019. Accepted for publication Dec 30, 2019.

doi: $10.21037 /$ jtd.2020.01.10

View this article at: http://dx.doi.org/10.21037/jtd.2020.01.10

\section{Background: aortic stenosis}

Aortic stenosis (AS) is one of the most common forms of valvular disease in Western countries (1-3). It shows a consistent association with age, with prevalence ranging from $0.2 \%$ in the $50-59$-year group to $9.8 \%$ in the 80-89-year cohort (4). Its prevalence is expected to increase due to higher life expectancy and population aging $(5,6)$. It is also the most common reason for heart valve replacement (7).

In a recent editorial paper (8), Eugene Braunwald put in perspective the medical advances in severe AS therapy over the last 50 years since the publication of his seminal study on AS natural history (9). Patients with severe AS had a good survival during a long latency period with "increasing obstruction and myocardial overload" until being about 60 years old. Then severe symptoms appeared and survival was poor, with most patients having heart failure, syncope and/or angina, and dying in a few years. With surgery being then the only available etiological treatment, the aim was to identify the patients approaching to such turning point to recommend surgery even with its associated risk with early prostheses.

Even though this typical course has been confirmed over the years (10-12), the survival curve has shown a clear-cut shift to the right with progressive symptoms appearing now in patients in their 7 th to 9 th decade (6). Medical advances have now led most AS patients to what Braunwald calls a "promised land" with a long survival and good quality 

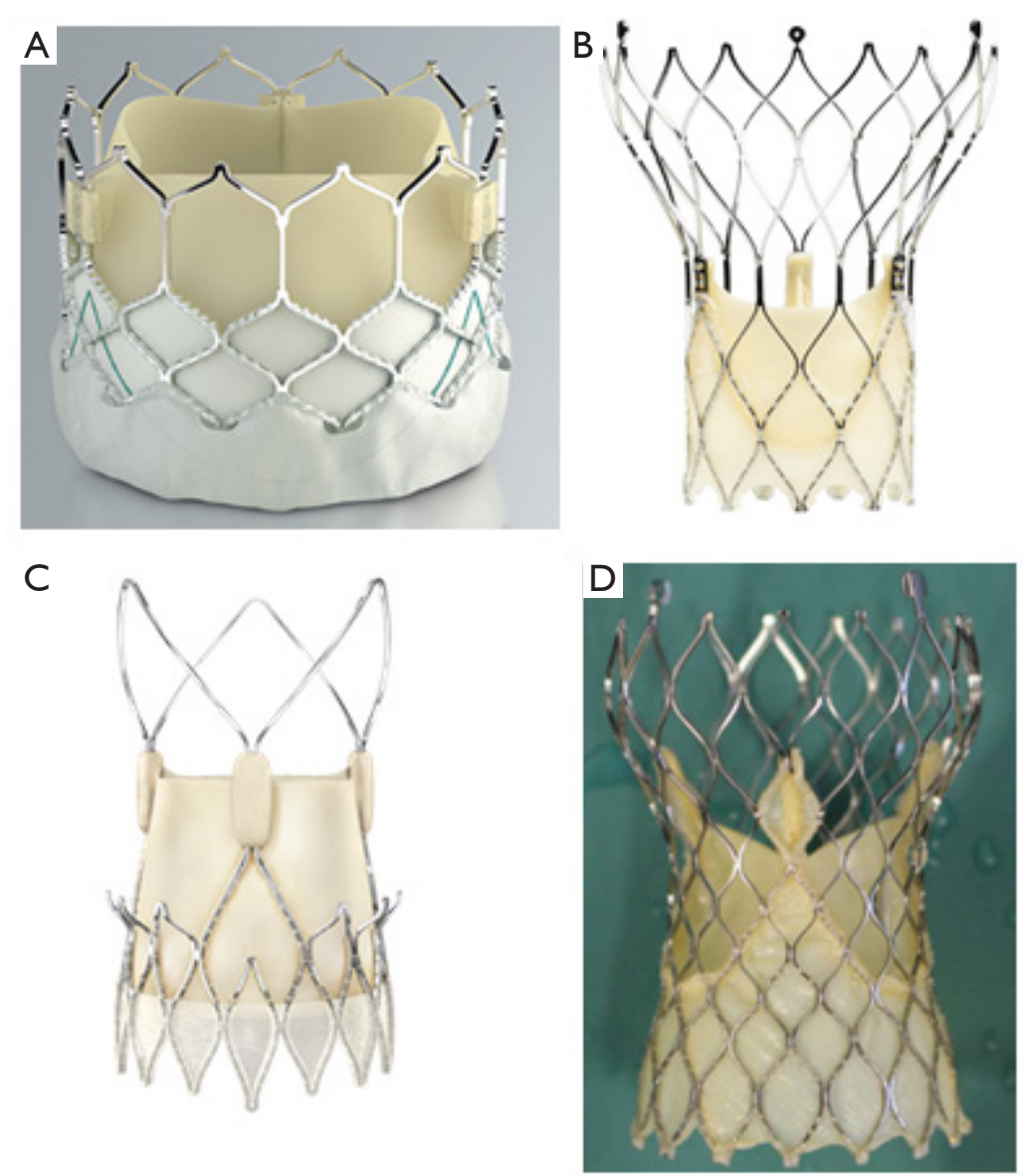

Figure 1 TAVR-currently available FDA and CE-marked prostheses. (A) Edwards-Sapien 3 copyright 2019; (B) Abbott Portico copyright 2019; (C) Boston Scientific ACURATE neo copyright 2019; (D) Medtronic Evolut R copyright 2019.

of life. This has been due to an increasing incidence of degenerative and calcified rather than rheumatic stenosis; substantial improvements in drug therapy for heart failure; use of imaging techniques including echocardiograms to identify severe cases; greatly improved surgical results; and particularly the huge advance offered by the transcatheter aortic valve replacement (TAVR). However, even in such a promised land, some issues are still unsolved and new challenges appear with TAVR. In the present review we shall discuss modern approaches to such issues and the current status of TAVR.

\section{Technical developments of TAVR}

The proof of concept for TAVR to treat AS in humans was published in 2002 by Alain Cribier and his colleagues, who used TAVR in a 57-year-old man with a cardiogenic shock due to severe AS and multiple comorbidities making surgery contraindicated (13). After this ground-breaking success, TAVR therapy has had a wide acceptation and a quick development along two complementary lines: technological advances and expanded indications.

From a technological point of view, the first valve was based on the balloon-expandable technique, previously used in stents. This line has been mainly followed by the successively improved models developed by Edwards Lifesciences (Sapien, Sapien XT, Sapien 3; see Figure 1). Just a few years later, the first cases of human use were published for a different model developed by the CoreValve company $(14,15)$. This was a self-expandable valve based on the use of nitinol, a nickel/titanium alloy showing a unique feature: shrinking at low temperatures and expanding at $37^{\circ} \mathrm{C}$. Such technical line has been mainly followed with several improved models (CoreValve, Evolut R, Evolut 
Table 1 Major randomized clinical trials for transcatheter aortic valve replacement (TAVR)

\begin{tabular}{|c|c|c|c|c|c|}
\hline Clinical trial & Publication year & Surgical risk & Type of valve & $\begin{array}{l}\text { Number of } \\
\text { patients }\end{array}$ & Main result \\
\hline PARTNER 1B (23) & 2010 & $\begin{array}{l}\text { Inoperable/extreme } \\
\text { risk }\end{array}$ & Balloon-expandable (SAPIEN) & 358 & $\begin{array}{l}\text { TAVR better than medical } \\
\text { therapy }\end{array}$ \\
\hline $\begin{array}{l}\text { CoreValve Extreme } \\
\text { Risk Pivotal Trial (24) }\end{array}$ & 2014 & Extreme risk & Self-expandable (CoreValve) & 506 & $\begin{array}{l}\text { TAVR better than medical } \\
\text { therapy }\end{array}$ \\
\hline $\begin{array}{l}\text { U.S. CoreValve High } \\
\text { Risk Pivotal Study (26) }\end{array}$ & 2014 & High risk & Self-expandable (CoreValve) & 795 & TAVR better than SAVR \\
\hline PARTNER 2A (27) & 2016 & Intermediate risk & Balloon-expandable (Sapien XT) & 2,032 & TAVR similar to SAVR \\
\hline SURTAVI (28) & 2017 & Intermediate risk & $\begin{array}{l}\text { Self-expandable (CoreValve and } \\
\text { Evolut R) }\end{array}$ & 1,746 & TAVR similar to SAVR \\
\hline PARTNER 3 (30) & 2019 & Low risk & Balloon-expandable (Sapien 3) & 1,000 & TAVR better than SAVR \\
\hline Low Risk Evolut (31) & 2019 & Low risk & $\begin{array}{l}\text { Self-expandable (CoreValve, } \\
\text { Evolut R, or Evolut PRO) }\end{array}$ & 1,468 & TAVR similar to SAVR \\
\hline
\end{tabular}

PRO; see Figure 1) by Medtronic.

Some other companies have also developed either balloon-expandable or self-expandable prostheses. Very recently, a large network meta-analysis has shown similar results with balloon- $v s$. self-expandable prostheses (16).

The major technical trends in TAVR development during the last decade have been: a gradually reduced use of other alternative access methods (including transapical access) in favor of the transfemoral access, the use of smaller catheters and different valve sizes tailored to anatomical needs, improved retrieving capacities to reposition the valve if needed, outer skirts to reduce paravalvular leaks, or improved delivery systems.

\section{Expanded indications and main clinical trials}

TAVR use achieved an enormous acceptation in Europe, particularly in Germany, in a very short time, and several national registries were started (17-20). As expected with any novel therapy, initial bulky valves for TAVR were implanted on a compassionate use in severely-ill, inoperable patients, with a high $(20 \%)$ immediate postoperative mortality (21). Since then, a number of large, welldesigned, randomized clinical trials have been performed, leading to gradually expanded indications (22). Main TAVR randomized trials are shown in Table 1.
In patients inoperable or with an extremely high operative risk, PARTNER (Placement of AoRtic TraNscathetER Valves) 1 B trial (NCT00530894) showed in 2010 a significant 1-year survival improvement with SAPIEN valve compared to medical therapy $(30.7 \%$ s. 50.7\%; HR 0.55; 95\% CI, 0.40-0.74; $\mathrm{P}<0.001$ ) (23). Also in patients with extremely high-risk, the CoreValve Extreme Risk Pivotal Trial (NCT01240902) found a significantly better outcome with TAVR compared to a pre-specified objective performance goal for a composite endpoint including all-cause mortality or major stroke after one year with a self-expanding CoreValve prosthesis (24).

Once the indication in extremely poor surgical candidates had been accepted, TAVR use was extended to high-risk patients [Society of Thoracic Surgeons (STS) score $>8 \%$; Logistic Euroscore I $>20 \%]$. Randomized clinical trials compared TAVR to the existing surgical aortic valve replacement (SAVR). The PARTNER 1A trial (NCT00530894) used a SAPIEN balloon-expandable valve and showed a similar 1-year mortality rate with TAVR and SAVR $(24.2 \%$ vs. $26.8 \%, \mathrm{P}=0.44 ; \mathrm{P}=0.001$ for non-inferiority); nevertheless, important differences were observed in periprocedural risks (25). Similarly, the U.S. CoreValve High Risk Pivotal Study (NCT01240902) compared the use of a self-expandable valve to SAVR, with TAVR achieving a significantly lower all-cause mortality 
rate at 1 year $(14.2 \%$ vs. $19.1 \% ; \mathrm{P}<0.001$ for non-inferiority; $\mathrm{P}=0.04$ for superiority) (26). Thus, the indication of both valves for high-risk patients was accepted by regulatory authorities.

The next step was to extend the accepted use to patients with an intermediate surgical risk (STS 4-8\%, Logistic Euroscore I $10-20 \%$ ) as an alternative to surgery. In PARTNER 2A trial (NCT01314313), a second-generation balloon-expandable valve (SAPIEN XT) was used. At 2 years, the rate of death from any cause or disabling stroke was similar with TAVR and SAVR (19.3\% vs. $21.1 \%$; HR 0.89; 95\% CI, 0.73-1.09; $\mathrm{P}=0.25$; $\mathrm{P}=0.001$ for noninferiority) (27). Similarly, a second generation selfexpandable valve (Evolut R) (and in some cases the first generation CoreValve prosthesis) was studied in the Surgical Replacement and Transcatheter Aortic Valve Implantation (SURTAVI) trial (NCT01586910). The rate of death or disabling stroke was also similar (12.6\% vs. $14 \%$; posterior probability of non-inferiority $>0.999)(28)$. Both balloonand self-expandable modern valves have been also approved by regulatory authorities.

\section{Use in patients at low surgical risk: latest clinical trials}

Taking into account the proved non-inferiority of TAVR compared to SAVR in patients at intermediate-toextreme surgical risk, should we expand the use of such a less invasive therapy to patients with a low surgical risk? There are several reasons favoring such a therapeutic drift, including a 10-35\% lower incidence of new-onset atrial fibrillation (32), a substantially lower incidence of postprocedural acute kidney injury (RR 0.66; 95\% CI, 0.47$0.94)(33)$, and an obviously less invasive procedure which is preferred by patients and results in a shorter ICU ( $2 \mathrm{vs}$. 4 days; $\mathrm{P}<0.001)$ and hospital stay (6 vs. 9 days; $\mathrm{P}<0.001)(27)$. Moreover, better TAVR results can be anticipated based on improved, recently developed devices and future valves under development (such as Acurate Neo, Lotus Edge, and others; see Figure 1) (34). Furthermore, increased operator experience will probably allow better results to be achieved; it has been shown that TAVR has a clear-cut learning curve and better TAVR results are achieved in high-volume centers $(35,36)$.

Existing randomized trials in low-risk patients are summarized in Table 1. The Nordic Aortic Valve Intervention Trial (NOTION; NCT01057173) was a randomized trial in an all-comers cohort of 280 elderly
( $\geq 70$ years) patients with severe AS requiring therapy and having no significant coronary disease that were randomized (1:1) to TAVR with a self-expandable prosthesis (CoreValve) or SAVR. The results are relevant because $81.8 \%$ of participants were low-risk patients (STS $<4 \%$ ). The combined rate of all-cause death, stroke, or myocardial infarction at 1 year was similar in both arms $(13.1 \% v s$. $16.3 \% ; \mathrm{P}=0.43$ for superiority). Mortality at 2 years was also similar. Pacemaker need was higher with TAVR whereas life-threatening bleeding, cardiogenic shock, acute kidney injury, and atrial fibrillation were more common with SAVR (29). In 2018, the Feasibility of Transcatheter Aortic Valve Replacement in Low-Risk Patients With Symptomatic, Severe Aortic Stenosis (Low Risk TAVR) trial (NCT02628899), a prospective non-randomized trial, compared low-risk patients with severe AS undergoing TAVR (various valves were used) with historical controls from the STS database using a propensity matching procedure. At 30 days, there were no deaths in the TAVR arm vs. $1.7 \%$ mortality in the SAVR arm; in-hospital stroke rate was null with TAVR vs. $0.6 \%$ with SAVR (36).

In the recent months two major trials have been published. The PARTNER 3 (NCT02675114) trial randomized 1000 patients with severe AS and low surgical risk (STS $<4 \%$ ) to transfemoral TAVR implantation of a third-generation balloon-expandable valve (SAPIEN 3) or SAVR (30). TAVR achieved strikingly better results. The composite endpoint of death, stroke, or rehospitalization at 1 year was significantly lower in the TAVR arm $(8.5 \% v s$. $15.1 \%$; $95 \%$ CI, -10.8 to $-2.5 ; \mathrm{P}<0.001$ for non-inferiority; HR, 0.54; 95\% CI, 0.37-0.79; $\mathrm{P}=0.001$ for superiority). At 30 days, TAVR was also better regarding stroke rate $(\mathrm{P}=0.02)$, death or stroke rate $(\mathrm{P}=0.01)$, new-onset atrial fibrillation rate $(\mathrm{P}<0.001)$, hospital stay duration $(\mathrm{P}<0.001)$ and rate of death or a low Kansas City Cardiomyopathy Questionnaire score $(\mathrm{P}<0.001)$.

The Evolut Low Risk Trial (NCT02701283) was a randomized non-inferiority trial of TAVR with a selfexpandable valve (CoreValve, Evolut R, or Evolut PRO) vs. SAVR in patients with severe AS with suitable anatomy for both TAVR and surgery and a low surgical risk (STS $<3 \%$ ). A composite primary endpoint including death or disabling stroke at 24 months was used. Results when 850 patients (out of 1403 with an attempted TAVR or SAVR) had reached 12-month follow-up, showed TAVR was non-inferior to SAVR (primary endpoint: $5.3 \%$ in TAVR arm vs. $6.7 \%$ in SAVR; posterior probability of non-inferiority $>0.999)$. At 30 days, TAVR showed lower rates of disabling stroke $(0.5 \%$ 
vs. $1.7 \%)$, bleeding complications (2.4\% vs. $7.5 \%)$, acute kidney injury (0.9\% vs. $2.8 \%)$, and atrial fibrillation $(7.7 \%$ vs. $35.4 \%)$ but more moderate/severe aortic regurgitation (3.5\% vs. $0.5 \%)$ and pacemaker need (17.4\% vs. $6.1 \%$ ) (37).

Although some concern has been expressed on a potential overselection in PARTNER 3 (one third of screened patients-compared to $15 \%$ in Evolut Low Risk Trial-were excluded with the main reason being anatomical features, including bicuspid valve) (32), and the significantly higher pacemaker need in Evolut Low Risk Trial should be also a cause of concern, such recent findings will undoubtedly lead to an expanded use of TAVR in a near future in low-risk patients. On the long-term, one may now even speculate on the possibility of a future role of TAVR in non-symptomatic AS patients showing signs of ventricular dysfunction if the results continue to improve in coming years.

Another major trial (NOTION 2, NCT02825134) is underway in 922 younger (i.e., <75 years old), low-risk patients, with its expected primary completion date being June 2020 (38). This trial which is being performed in Nordic countries, will provide important results because the lower risk profile is not necessarily associated to a younger age since AS remains an old-age disorder (39).

A recent meta-analysis of TAVR trials in low-risk patients, based on NOTION, PARTNER 3, and Evolut Low Risk trials, has shown no significant difference between TAVR and SAVR in all-cause mortality (RR 0.86; 95\% CI, $0.61-1.19 ; \mathrm{P}=0.36$ ) and stroke (RR 0.82; 95\% CI, 0.48-1.43; $\mathrm{P}=0.49$ ) (40). However, TAVR was associated to a lower incidence of other complications (such as acute kidney injury, new-onset atrial fibrillation, and life-threatening or disabling bleeding), but a higher rate of paravalvular leak and need for pacemaker (40). Also recently, an updated meta-analysis of seven major randomized trials comparing TAVR with SAVR in patients at all risk levels (including low-risk PARTNER and Evolut Low Risk trials) has recently been published (41). Overall results show that, compared with SAVR, TAVR results in lower all-cause mortality (HR 0.88; 95\% CI, 0.78-0.99; $\mathrm{P}=0.030$ ) and stroke (HR 0.81; 95\% CI, 0.68-0.98; $\mathrm{P}=0.028$ ) rates at 2 years, across the full risk spectrum ( $\mathrm{P}$ for interaction=0.410) and irrespective of prosthesis type $(\mathrm{P}$ for interaction $=0.674)(41)$. However, TAVR was associated to a higher risk of major vascular complications (HR 1.99; $\mathrm{P}=0.001$ ] and permanent pacemaker implantations $(\mathrm{HR} 2.27 ; \mathrm{P}<0.001)$ compared to SAVR.

Nevertheless, a number of challenges need still to be addressed before TAVR can be used in low-risk patients on a routine basis: (I) updated international guidelines to take into account latest evidence. (II) Main complications will need to be addressed, particularly those having shown a higher incidence with TAVR in some trials, i.e., permanent pacemaker implantation, paravalvular leak, and stroke (and its potential prevention by using anti-embolic protection devices). This is particularly important when treating younger and lower-risk patients who have a longer life expectancy. (III) The appropriate role of TAVR in patients with concomitant cardiac ischemic disease should be addressed. (IV) Durability of bio-prosthetic implanted valves. We shall briefly discuss these issues in the following paragraphs.

\section{Guidelines recommendations}

In general terms, aortic valve interventions are recommended for patients with severe AS and direct objective imaging evidence or surrogate symptomatic measures of left ventricular dysfunction (42). The most relevant issue for the present review is the decision to opt for TAVR or SAVR. Latest versions of both European (ESC/ EACTS) (43) and American (AHA/ACC) (44) guidelines were issued in 2017 , i.e., before the advent of the last generation TAVR prostheses and before the publication of the recent randomized trials in patients at low surgical risk. Thus, updated recommendations are to be expected once such new evidence is taken into account, and such guidelines will be needed to assess the best current role of TAVR in AS.

In spite of being supported by just a C-level evidence, both guidelines include a class I recommendation for each TAVR candidate to be presented to a multidisciplinary Heart Team to establish the presence of symptoms attributable to a severe AS and to decide the most appropriate management $(43,44)$. The Heart Team is possibly one of the most critical current recommendations.

Current American guidelines recommend (class I) TAVR in inoperable patients. For patients with high surgical risk, both TAVR and SAVR (both, class I) are recommended, as well as the involvement of the Heart Team to assess "surgical risk, patient frailty, comorbid conditions, and patient preferences and values" (44). Although only limited data are available, some evidence suggest that such values and preferences for TAVR/SAVR are not uniform; thus a well-informed and shared decision-making with patients is in order (45). SAVR (class I) and TAVR (class IIa) along 
with Heart Team assessment are now also recommended for patients with intermediate surgical risk. Only SAVR is recommended at this point for low-risk patients (class I).

Similarly, European guidelines recommend (class I) TAVR in inoperable patients. Both TAVR and SAVR are recommended in high-risk patients (both class I), and in intermediate-risk patients (TAVR class IIa, SAVR class I). For high or intermediate-risk patients "(STS or EuroSCORE II $\geq 4 \%$ or logistic EuroSCORE I $\geq 10 \%$ or other risk factors not included in these scores such as frailty, porcelain aorta, sequelae of chest radiation), the decision between SAVR and TAVR should be made by the Heart Team according to the individual patient characteristics, with TAVR being favored in elderly patients suitable for transfemoral access" (43). TAVR is currently not yet recommended for low-risk patients (class I). Other national guidelines have reported similar recommendations (46).

\section{Permanent pacemaker implantation}

Currently, the need for periprocedural permanent pacemaker implantation (PPM) is one of the most common complications of TAVR (47). With first generation devices, a landmark meta-analysis of 32 studies (5,258 patients) found a $15 \%$ incidence of PPM $(25.8 \%$ with CoreValve self-expandable valve $v s$. $6.5 \%$ with Sapien balloonexpandable prosthesis) (48). Another review of 49 studies (16,063 patients) reported an overall rate of $13 \%$ of patients requiring PPM, and PPM was 5 times more common with CoreValve device than with Sapien valve (49). In another meta-analysis of 41 studies (11,240 patients) PPM rate ranged from $2 \%$ to $51 \%$, with median rate being $28 \%$ with Medtronic CoreValve and 6\% with Edwards Sapien (47). The lower risk of balloon-expandable valves has been confirmed by a randomized trial $(17.3 \%$ vs. $47.6 \%$, $\mathrm{P}<0.001)(50)$. Rates with new generation prostheses are highly variable (ranging from $2.3 \%$ to $26.1 \%$ ) (51). The higher PPM incidence with self-expandable valves appears to be due to increased radial force on the left ventricular outflow tract by the expanded nitinol device (34).

Prognostic consequences of PPM in TAVR remain controversial. While a meta-analysis did not find a negative impact of PPM on 1-year survival (52), subsequent results from the large American TVT registry have shown that PPM implantation results in a longer hospital and ICU stay and a 1 -year increased mortality (24.1\% vs. 19.6\%; HR 1.31; 96\% CI, 1.09-1.58) (53). The long-term impact of PPM has not been assessed.
Improvements in newer generation balloon- and selfexpandable prosthesis - with features consisting in sealing skirts or repositionable and retrievable devices-have been mainly focused on reducing paravalvular leaks (PVL), but have not much aimed at reducing PPM need (54). This is probably due to the fact that PVLs were early shown to be clearly associated to higher mortality, whereas prognostic impact of PPM remains unclear. Accordingly, incidence of PPM use has not declined with newer-generation valves. For example, Sapien 3 valve features an anti-PVL external skirt that probably causes greater radial forces on the annulus. In fact, Sapien 3 multicenter registries have found PPM rates ranging from $10.1 \%$ to $14.1 \%$, which are more than twice the rate observed with its predecessors Sapien/Sapien XT (55-58). A higher implantation ( $<25 \%$ of ventricular portion) appears to mitigate the problem; further data are needed to confirm that this can be applied without increasing other complications such as valve migration or PVL and no trade-off effect is observed between PPM and PVL. A Portico repositionable and resheathable annular functioning self-expanding prosthesis was specifically designed to reduce PPM need, allowing resheathing and sealing without requiring a deep positioning in left ventricular outflow tract. Initial results at 30 days showed PPM was needed in $9.8 \%$ of patients $(59,60)$. A more recent 1 -year study has reported a $14.7 \%$ PPM rate (61). Higher implantation depth has also achieved a lower PPM rate with CoreValve (62). Newergeneration self-expandable valves have resulted in a $16.4 \%$ rate with Evolut R (63) and 11.8\% with Evolut PRO (64), whereas an encouraging $4.9 \%$ rate has been reported with the new Edwards Centera self-expanding valve featuring a low profile with a frame protruding less into the outflow tract (65) and a 9.9\% rate has been obtained with a new Symetis Acurate Neo/TF self-expandable valve with a leaflet valve in a supra-annular position and a sealing-skirt on the outer and inner surface of the stent (66). The recently published trials in low-risk patients have shown similar results to previous trials in patients at higher risk, with PPM rates being $17.4 \%$ (significantly higher than SAVR, 6.1\%) in Evolut Low Risk Trial (self-expandable valve) and 6.6\% (and interestingly, not significantly different from SAVR, 4.1\%) in PARTNER 3 (balloon-expandable valve), respectively.

Besides the use of a self-expandable device, main predictors of PPM need in TAVR are pre-existing right bundle-branch block, male sex, calcification, depth of implantation (with some valve-specific cut-off values having been proposed), first-degree atrioventricular block, and 
oversizing of the aortic annulus/left ventricular outflow tract (67).

Importantly, pacemaker dependency does not appear to persist in the long-term after TAVR in all patients. In cohort studies of patients receiving a mix of TAVR prostheses, long-term dependency ranged from $27 \%$ (68) to $68.4 \%$ (69). A study in patients receiving CoreValve self-expandable valve showed a $46.7 \%$ long-term dependency (70), whereas in a cohort of patients undergoing TAVR with a Lotus valve, $57 \%$ and $38 \%$ of patients were pacemakerdependent at 30-day and 1-year, respectively (71). Thus, a transient effect of inflammation, edema, ischemia or direct injury may show a subsequent recovery in a substantial number of patients, suggesting a short period of rhythm monitoring could be advisable before PPM is implanted after TAVR, in order to avoid unnecessary PPM when attempting to shorten hospital stays.

A number of recommendations and guidelines have been proposed to reduce PPM needs in TAVR, based on pre-procedural rhythm screening and patient/ valve type selection, intraprocedural high implantation procedures, and post-procedural monitoring (72); but no consensus has yet been reached. A recent paper by an expert panel has provided a well-founded algorithm that could be a framework for future research and guideline recommendations (73).

\section{Paravalvular leak}

Paravalvular leak has been one of the most common complications of TAVR and probably the main driver for the development of improved device designs. Moderateto-severe PVL is associated to higher short- and long-term complications and mortality (17,27,74-78). Although some findings suggest that even mild PVL could have an adverse impact on survival, this has not consistently been observed across studies and meta-analyses (74-76,79,80).

Using first-generation prostheses, the overall mild PVL rate ranged from $20 \%$ to $80 \%$, with moderate-tosevere PVL occurring in $5 \%$ to $22 \%$ of patients (81). In early pivotal trials, 1-year moderate-to-severe PVL rates were $6.8 \%(25)$ and $10.5 \%(23)$ with the Sapien balloon-expandable valve, and $4.2 \%$ (24) and $6.1 \%$ (26) with the CoreValve self-expandable valve. A metaanalysis of 45 studies $(11,244$ patients) reported a pooled $11.7 \%$ rate, with a significantly higher risk with CoreValve vs. Sapien (16.0\% vs. 9.1\%, $\mathrm{P}=0.005)$ (77). The significantly higher risk with self-expandable vs. balloon-expandable valves has been also shown in another meta-analysis (20 studies, 11,244 patients) (82) and angiographically in a single randomized trial $(18.3 \%$ vs. $4.1 \%, \mathrm{P}<0.001)(50)$. Despite a higher presence of more-than-mild PVL in self-expandable valves, direct comparisons of the two technologies have shown no impact in mortality.

The rate of moderate-to-severe PVL has dramatically decreased with new-generation valves. A $2 \%$ (83) or 3.4\% (55) rate has been reported with Edwards Sapien 3, whereas early findings showed more-than-mild PVL at 30 days to be absent $(0 \%)$ in patients receiving the CoreValve Evolut PRO device (64); and a single patient (1.0\%) had moderate PVL with none having severe PVL with the Lotus valve (84). Pilgrim $e t a l$. used a propensity score matched analysis of 391 matched pairs of patients to compare early versus newer generation TAVR devices. Moderate-to-severe PVL rate was $12.1 \%$ vs. $3.1 \%, \mathrm{P}<0.001$ (85). Nevertheless, mild PVL is still frequently associated even to newer devices (64).

Recent trials in low-risk patients demonstrate very low PVL rates. In PARTNER 3 trial (new-generation Sapien 3 balloon-expandable valve) 30-day moderate-to-severe PVL rates with TAVR vs. SAVR were $0.8 \%$ vs. none (n.s.) (30). In Evolut Low Risk Trial (CoreValve, Evolut R, or Evolut PRO self-expanding valves) 30 -day rates were $3.5 \%$ vs. $0.5 \%$, respectively (31). Such findings confirm both the risk decrease with new-generation valves and the higher risk with self-expanding prostheses.

Besides an increased overall operator experience in prosthesis positioning, two main causes may explain the dramatic decrease in PVL in recent years: improved design and pre-procedural imaging for annulus sizing.

The design of new-generation valves is substantially improved. Manufacturers have added a cuff to the inflow portion of the valve (Sapien, Lotus) or an external sealing system (Evolut or Portico). Furthermore, Evolut R has a shorter height and is retrievable and repositionable after a partial deployment, and Evolut PRO has an external pericardial cover on the lower 2 rows of stent frame cell to fill the gap to the landing zone (81). The Portico valve features a porcine pericardium sealing cuff to encapsulate irregular calcium nodules $(86,87)$. The ACURATE neo prosthesis (Symetis, Boston Scientific) has upper crowns for supra-annular anchoring and a sealing pericardial skirt $(88,89)$. However, as previously mentioned, taking into account that PPM implantation has not decreased or has even increased with the new-generation valves, some concerns exist about a potential trade-off between PVL and 
PPM complications.

Routine use of improved echocardiography techniques and particularly multislice computed tomography (MSCT) in pre-procedural planning to measure annulus dimensions to select valve size and model appears to be critical (90). Furthermore, non-enhanced MSCT helps to evaluate anatomical considerations such as coronary ostia or calcification distribution including the left ventricular outflow tract $(81,91)$. Contrast-related kidney dysfunction is, though, a potential limitation.

Besides post-procedural echocardiographic imaging, some biomarkers have been proposed to predict PVL immediately after TAVR. A loss of high molecular weight multimers of von Willebrand factor (vWF) is observed with significant PVL, due to molecular unfolding and exposition to proteolytic enzymes as a consequence of the turbulent blood flow $(92,93)$. This results in less haemostatic capacity of $\mathrm{vWF}$ and causes a longer closure time with adenosine diphosphate (CT-ADP). Both CT-ADP and vWF multimer ratio predict post-TAVR PVL $(94,95)$.

A trace or mild PVL usually requires no corrective measures. If a more-than-mild PVL is detected after TAVR, immediate correction is needed, by means of additional balloon postdilation $(96,97)$, a valve-in-valve procedure (96-99), or snearing of the valve. A regression of PVL severity has been reported after a follow-up period in patients having received SAPIEN 3 (100) or CoreValve devices (101).

\section{Stroke and embolic protection}

Stroke is one of the most feared complications following aortic valve replacement. New-onset periprocedural lesions are found in cerebral magnetic resonance imaging in a high proportion of patients undergoing TAVR, ranging from $68 \%$ to $85 \%$ across studies (102-104). A meta-analysis of 25 studies (1,225 patients) found the pooled rate to be $77.5 \%$ (95\% CI, $71.7-83.3 \%$ ), with multiple lesions in $59.5 \%$ of patients and a mean number of lesions of 4.2 (3.4-5.0) (105). Fortunately, most of such lesions are the so-called "silent strokes" and are not associated to clinical signs and, in fact, its significance remains unclear.

Incidence of clinically overt strokes in early pivotal studies was $2.8-5.0 \%$ (23-26). A meta-analysis of 25 multicenter registries and 33 single-center studies found an overall 30day clinical ictus rate of $2.8 \%$, and a decline in stroke risk with experience and technological advancement (106).
Recent trials in low-risk patients demonstrate very low stroke rates, with TAVR being significantly superior to SAVR. In PARTNER 3 trial (new-generation Sapien 3 balloon-expandable valve) 30-day and 1-year stroke rates with TAVR vs. SAVR were $0.6 \%$ vs. $2.4 \%$; HR 0.25 ; $95 \%$ CI, $0.07-0.88 ; \mathrm{P}=0.02$ ) and $1.2 \%$ vs. $3.1 \%$ (HR $0.38 ; 95 \%$ CI, 0.15-1.00) (30). In Evolut Low Risk Trial (CoreValve, Evolut R, or Evolut PRO self-expanding valve) 30-day and 2-year disabling stroke rates with TAVR vs. SAVR were $0.5 \%$ vs. $1.7 \%$ (difference, -1.2 percentage points; $95 \%$ credible interval -2.4 to -0.2 ) and $1.1 \%$ vs. $3.5 \%$ (difference, $-2.3 ;-4.8$ to -0.4 ) (31). Nevertheless, methods to prevent neurologic embolic complications are needed, because periprocedural stroke is associated to a substantially increased in-hospital and 1-year mortality rates and to a reduced quality of life and severe disability in survivors (107).

Several embolic protection devices have been developed and tested. A detailed review of their types and results has been recently published in Fournal of Thoracic Disease (108). Such mesh-based devices aim at preventing procedural debris-including thrombi, valve calcification/tissue, arterial wall fragments- to reach cerebral vessels and cause cerebrovascular insults. Two main types are available. Firstly, those deflecting debris include Embrella Embolic Deflector (Edwards Lifesciences, CA, USA) featuring two heparin-coated membranes that are deployed in the aortic arch and cover brachiocephalic and left common carotid arteries; and TriGuard (Keystone Heart, Israel), a nitinolcoated device covering also the left subclavian artery. Secondly, filter-type devices retain the embolized material thus avoiding also potential peripheral embolisms. Apart from Embol-X (Edwards Lifesciences, CA, USA), a single filter device which is inserted through a mid-sternotomy during transaortic TAVR, to be deployed in ascending aorta, the Sentinel (Boston Scientific Corporation, CA, USA) (previously named Montage, Claret Medical) is available. It features a dual filter with $140 \mu \mathrm{m}$ pores to cover brachiocephalic and left common carotid arteries. Sentinel use has been recently combined with a single left vertebral filter (Wirion, Allum Medical, Israel) to cover the remaining $20 \%$ of total brain perfusion for posterior circulation not covered by Sentinel device; recovered debris showed equal amounts in both devices (107).

Such devices are safe and have proved effective to filtrate debris and to reduce the volume of ischemic lesions, as suggested by a meta-analysis including 1,170 patients. No differences could be demonstrated, however, 
in terms of clinically evident stroke (109). A more recent meta-analysis of 8 studies (1,285 patients) confirmed the significant reduction in volume per lesion and in total lesion volume, and found a lower rate of 30-day stroke [OR 0.55 (95\% CI, 0.31-0.98), $\mathrm{P}=0.04]$ when using embolic protection devices (110). However, the latter resultsthat are very close to the upper CI limit-were mainly driven by a single non-randomized, propensity scorematched study using the Sentinel device (111). Such metaanalyses did not find any significant difference in mortality rate between patients undergoing TAVR with or without cerebral protection devices. A single randomized controlled trial with the Sentinel device that assessed mortality, did not find differences in mortality and in the primary combined endpoint including all major adverse cardiac and cerebrovascular events (112). Statistical methods used in other studies are limited, and the quality of evidence supporting clinical efficacy is still low, in spite of a clear and statistically significant reduction in lesions volume (112). There is an urgent need of further evidence on this issue.

\section{TAVR and cardiac ischemic disease}

Coronary artery disease (CAD) is very common in patients with severe AS (40-75\%) (113), including those undergoing TAVR [about $75 \%$ of patients in PARTNER 1 studies $(23,25)$ and about $50 \%$ in large TAVR registries $(114,115)]$. This is not surprising because degenerative AS and atherosclerosis share many risk factors and pathogenic mechanisms. While a meta-analysis of 7 studies $(2,472$ patients) did not prove a mid-term effect of CAD on TAVR outcomes (116), a more recent one (15 studies, 8,013 patients) has shown no impact on 30-days mortality but a significant adverse impact on 1-year mortality (OR 1.21; $95 \% \mathrm{CI}, 1.07-1.36 ; \mathrm{P}=0.002)(117)$. In a third meta-analysis (6 studies, 3,107 patients), a residual SYNTAX (Synergy Between PCI With Taxus and Cardiac Surgery)-score cut-off value $(<8)$ after coronary revascularization has been shown to predict a significantly higher mortality (OR 1.69; $95 \%$ CI, 1.26-2.28; $\mathrm{P}<0.001)$ (118). The eagerly awaited results from the ACTIVATION trial (ISRCTN75836930) (119) will help to establish recommendations about the need and appropriate extent of CAD revascularization prior to TAVR.

As the TAVR indications expand to include younger and lower-risk patients with longer life expectancies, it is important to establish an appropriate management of CAD because coronary arteries can have to be re-accessed later on in these patients, which has proved challenging, particularly with self-expandable devices (120). An algorithm has been proposed to facilitate coronary access after TAVR (120).

\section{Durability}

The adoption of TAVR for younger and lower-risk patients, with a longer life expectancy, raises concerns about durability. Significant deterioration of surgical bioprostheses commonly begins about 10 years after implantation, but increases dramatically during the second post-procedural decade (121). Instead of bioprostheses, surgeons have traditionally preferred using the drug therapy required by mechanical valves to manage thrombotic risk, in exchange for longer prosthesis durability in such patients. TAVR is a relatively new technique; therefore, few long-term data are available to assess the durability of both porcine and bovine valves. Furthermore, early use was restricted to high-risk patients and the poor long-term survival of such population beyond 5 years has limited durability assessments (122).

Potential factors having an impact on durability are physical (tissue characteristics, anticalcification treatment, valve design, valve effective area orifice, postimplantation transvalvular gradient, calcifications, postdilation, asymmetric annulus with leaflet deformation...) and clinical/metabolic (age, diabetes, lipid abnormalities, calcium/phosphor metabolism...) (123-125).

Early 5 -year results of PARTNER 1 trial were reassuring, with no patient showing a deterioration requiring reintervention (78). Results were equally favorable in the high-risk pivotal trial with the CoreValve at 3 years (126). Five-year results of the ADVANCE trial in 996 high-risk patients undergoing TAVR with a self-expandable valve showed valve dysfunction in only $2.5 \%$ of patients. Fiveyear results in a multicenter Italian registry were also reassuring (127). A meta-analysis of 13 observational studies $(8,914$ patients) with a $1.6-5$ years follow-up period reported valve deterioration in only 0 to 1.34 per 100 patient-years (126). Similarly, Toggweiler et al. found moderate prosthetic valve dysfunction in $3.4 \%$ of 88 patients after a 5 -year follow-up (127). The UK registry reported an $8.7 \%$ deterioration rate after a mean follow-up of 6.1 years (128).

The problem of lack of consistency in structural valve deterioration (SVD) definition was addressed in 2017 through a consensus statement of European Association of Percutaneous Cardiovascular Interventions (EAPCI) endorsed by the European Society of Cardiology (ESC) and the European Association for Cardio-Thoracic 
Surgery (EACTS) (129), in which concepts and grades of "hemodynamic SVD" and "morphological SVD" are defined; and in 2018 by the Valve-in-Valve International Data (VIVID) group (129). Using such new definitions, severe SVD and moderate/severe SVD rates have been $2.5 \%$ and $13.3 \%$ at 5 years in the FRANCE 2 registry (129); and $2.4 \%$ and $8.3 \%$ at 8 years in the local Italian REPLACE registry (130). Similar findings have been reported in other recent studies using such definitions (122,131-135). Thus, mid-term follow-up data are reassuring, but 10- and 15-year data are eagerly awaited to inform our current decisions on TAVR use in low-risk patients.

\section{Conclusions}

The advent of TAVR has dramatically changed the landscape of severe AS therapy in the last decade. The recent results of large well-designed randomized trials in patients with low surgical risk can be expected to result in an expansion of its indications in future guidelines updates. While PVL issue appears to be decreasing with improved device designs being currently introduced, newer-generation prostheses will have to address the unsolved issue of PPM implantation requirements. Stroke incidence is low, but its adverse impact is a reason of concern; further evidence on clinical performance of current embolic protection devices and development, and test of novel devices are needed. The role of TAVR in patients with concomitant cardiac ischemic disease should also be better defined. Availability of durability data in the next few years will be crucial to establish the role of current prostheses in low-risk patients with a longer life expectancy, or the need to develop other devices.

\section{Acknowledgments}

Funding: None.

\section{Footnote}

Provenance and Peer Review: This article was commissioned by the Guest Editor (Ion S. Jovin) for the series "Interventional Cardiology" published in Fournal of Thoracic Disease. The article was sent for external peer review organized by the Guest Editor and the editorial office.

Conflicts of Interest: All authors have completed the ICMJE uniform disclosure form (available at http://dx.doi. org/10.21037/jtd.2020.01.10). The series "Interventional
Cardiology" was commissioned by the editorial office without any funding or sponsorship. MVN reports other from Abbott, Medtronic, and Boston Scientific outside the submitted work; SF reports other from Abbott and Edwards Lifesciences outside the submitted work; SMP was supported by research grants by the Cardiopulmonary Institute (CPI) and the German Centre for Cardiovascular Research (DZHK). The other authors have no other conflicts of interest to declare.

Ethical Statement: The authors are accountable for all aspects of the work in ensuring that questions related to the accuracy or integrity of any part of the work are appropriately investigated and resolved.

Open Access Statement: This is an Open Access article distributed in accordance with the Creative Commons Attribution-NonCommercial-NoDerivs 4.0 International License (CC BY-NC-ND 4.0), which permits the noncommercial replication and distribution of the article with the strict proviso that no changes or edits are made and the original work is properly cited (including links to both the formal publication through the relevant DOI and the license). See: https://creativecommons.org/licenses/by-nc-nd/4.0/.

\section{References}

1. Osnabrugge RLJ, Mylotte D, Head SJ, et al. Aortic Stenosis in the Elderly. J Am Coll Cardiol 2013;62:1002-12.

2. Kanwar A, Thaden JJ, Nkomo VT. Management of Patients With Aortic Valve Stenosis. Mayo Clin Proc 2018;93:488-508.

3. Zakkar M, Bryan AJ, Angelini GD. Aortic stenosis: diagnosis and management. BMJ 2016;355:15425.

4. Eveborn GW, Schirmer H, Heggelund G, Lunde P, Rasmussen K. The evolving epidemiology of valvular aortic stenosis. The Tromsø Study. Heart 2013;99:396-400.

5. d'Arcy JL, Prendergast BD, Chambers JB, Ray SG, Bridgewater B. Valvular heart disease: the next cardiac epidemic. Heart 2011;97:91-3.

6. Bonow RO, Greenland P. Population-wide trends in aortic stenosis incidence and outcomes. Circulation 2015;131:969-71.

7. Martinsson A, Li X, Andersson C, Nilsson J, Smith JG, Sundquist K. Temporal Trends in the Incidence and Prognosis of Aortic Stenosis. Circulation 2015;131:988-94.

8. Braunwald E. Aortic Stenosis: Then and Now. Circulation 2018;137:2099-100.

9. Ross J, Braunwald E. Aortic stenosis. Circulation 
1968;38:61-7.

10. Bach DS, Siao D, Girard SE, et al. Evaluation of patients with severe symptomatic aortic stenosis who do not undergo aortic valve replacement: the potential role of subjectively overestimated operative risk. Circ Cardiovasc Qual Outcomes 2009;2:533-9.

11. Bouma BJ, van Den Brink RB, van Der Meulen JH, et al. To operate or not on elderly patients with aortic stenosis: the decision and its consequences. Heart 1999;82:143-8.

12. Kelly TA, Rothbart RM, Cooper CM, et al. Comparison of outcome of asymptomatic to symptomatic patients older than 20 years of age with valvular aortic stenosis. Am J Cardiol 1988;61:123-30.

13. Cribier A, Eltchaninoff H, Bash A, et al. Percutaneous transcatheter implantation of an aortic valve prosthesis for calcific aortic stenosis: first human case description. Circulation 2002;106:3006-8.

14. Grube E, Laborde JC, Zickmann B, et al. First report on a human percutaneous transluminal implantation of a selfexpanding valve prosthesis for interventional treatment of aortic valve stenosis. Catheter Cardiovasc Interv 2005;66:465-9.

15. Laborde JC, Borenstein N, Behr L, Farah B, Fajadet J. Percutaneous implantation of an aortic valve prosthesis. Catheter Cardiovasc Interv 2005;65:171-4.

16. Osman M, Ghaffar YA, Saleem M, et al. Meta-Analysis Comparing Transcatheter Aortic Valve Implantation With Balloon Versus Self-Expandable Valves. Am J Cardiol 2019;124:1252-6.

17. Gilard M, Eltchaninoff H, Iung B, et al. Registry of transcatheter aortic-valve implantation in high-risk patients. N Engl J Med 2012;366:1705-15.

18. Thomas M, Schymik G, Walther T, et al. One-Year Outcomes of Cohort 1 in the Edwards SAPIEN Aortic Bioprosthesis European Outcome (SOURCE) Registry. Circulation 2011;124:425-33.

19. Eltchaninoff H, Prat A, Gilard M, et al. Transcatheter aortic valve implantation: early results of the FRANCE (FRench Aortic National CoreValve and Edwards) registry. Eur Heart J 2011;32:191-7.

20. Beckmann A, Hamm C, Figulla H, et al. The German Aortic Valve Registry (GARY): A Nationwide Registry for Patients Undergoing Invasive Therapy for Severe Aortic Valve Stenosis. Thorac Cardiovasc Surg 2012;60:319-25.

21. Figulla HR, Franz M, Lauten A. The history of Transcatheter Aortic Valve Implantation (TAVI)-A personal view over 25 years of development. Cardiovasc Revasc Med 2019. [Epub ahead of print].
22. Al-Azizi K, Hamandi M, Mack M. Clinical trials of transcatheter aortic valve replacement. Heart 2019;105:s6-9.

23. Leon MB, Smith CR, Mack M, et al. Transcatheter Aortic-Valve Implantation for Aortic Stenosis in Patients Who Cannot Undergo Surgery. N Engl J Med 2010;363:1597-607.

24. Popma JJ, Adams DH, Reardon MJ, et al. Transcatheter Aortic Valve Replacement Using a Self-Expanding Bioprosthesis in Patients With Severe Aortic Stenosis at Extreme Risk for Surgery. J Am Coll Cardiol 2014;63:1972-81.

25. Smith CR, Leon MB, Mack MJ, et al. Transcatheter versus Surgical Aortic-Valve Replacement in High-Risk Patients. N Engl J Med 2011;364:2187-98.

26. Adams DH, Popma JJ, Reardon MJ, et al. Transcatheter aortic-valve replacement with a self-expanding prosthesis. N Engl J Med 2014;370:1790-8.

27. Leon MB, Smith CR, Mack MJ, et al. Transcatheter or surgical aortic-valve replacement in intermediate-risk patients. N Engl J Med 2016;374:1609-20.

28. Reardon MJ, Van Mieghem NM, Popma JJ, et al. Surgical or transcatheter aortic-valve replacement in intermediaterisk patients. N Engl J Med 2017;376:1321-31.

29. Thyregod HGH, Steinbrüchel DA, Ihlemann N, et al. Transcatheter versus surgical aortic valve replacement in patients with severe aortic valve stenosis: 1 -year results from the all-comers NOTION randomized clinical trial. J Am Coll Cardiol 2015;65:2184-94.

30. Mack MJ, Leon MB, Thourani VH, et al. Transcatheter aortic-valve replacement with a balloon-expandable valve in low-risk patients. N Engl J Med 2019;380:1695-705.

31. Popma JJ, Michael Deeb G, Yakubov SJ, et al. Transcatheter aortic-valve replacement with a selfexpanding valve in low-risk patients. N Engl J Med 2019;380:1706-15.

32. Overtchouk P, Prendergast B, Modine T. Why should we extend transcatheter aortic valve implantation to low-risk patients? A comprehensive review. Arch Cardiovasc Dis 2019;112:354-62.

33. Arora S, Strassle PD, Ramm CJ, et al. Transcatheter Versus Surgical Aortic Valve Replacement in Patients With Lower Surgical Risk Scores: A Systematic Review and Meta-Analysis of Early Outcomes. Heart Lung Circ 2017;26:840-5.

34. Sanchez CE, Yakubov SJ, Arshi A. Innovations in Transcatheter Valve Technology: What the Next Five Years Hold. Interv Cardiol Clin 2018;7:489-501. 
35. Wassef AWA, Rodes-Cabau J, Liu Y, et al. The Learning Curve and Annual Procedure Volume Standards for Optimum Outcomes of Transcatheter Aortic Valve Replacement: Findings From an International Registry. JACC Cardiovasc Interv 2018;11:1669-79.

36. Cormican D, Jayaraman A, Villablanca P, et al. TAVR Procedural Volumes and Patient Outcomes: Analysis of Recent Data. J Cardiothorac Vasc Anesth 2020;34:545-50.

37. Waksman R, Rogers T, Torguson R, et al. Transcatheter Aortic Valve Replacement in Low-Risk Patients With Symptomatic Severe Aortic Stenosis. J Am Coll Cardiol 2018;72:2095-105.

38. Comparison of Transcatheter Versus Surgical Aortic Valve Replacement in Younger Low Surgical Risk Patients With Severe Aortic Stenosis - Tabular View - ClinicalTrials.gov. Available online: https:/clinicaltrials.gov/ct2/show/record/ NCT02825134? term=NCT02825134\&draw=1\&rank=1. Accessed September 12, 2019.

39. Michel M, Didier R, Bouleti C, et al. Transcatheter aortic valve implantation in patients with severe aortic stenosis: Does lower-risk profile mean a young patient? Arch Cardiovasc Dis 2019;112:293-5.

40. Al-Abdouh A, Upadhrasta S, Fashanu O, et al. Transcatheter aortic valve replacement in low-risk patients: A meta-analysis of randomized controlled trials. Cardiovasc Revasc Med 2019. [Epub ahead of print].

41. Siontis GCM, Overtchouk P, Cahill TJ, et al.

Transcatheter aortic valve implantation vs. surgical aortic valve replacement for treatment of symptomatic severe aortic stenosis: an updated meta-analysis. Eur Heart J 2019;40:3143-53.

42. Everett RJ, Clavel M-A, Pibarot P, et al. Timing of intervention in aortic stenosis: a review of current and future strategies. Heart 2018;104:2067-76.

43. Baumgartner H, Falk V, Bax JJ, et al. 2017 ESC/EACTS Guidelines for the management of valvular heart disease. Eur Heart J 2017;38:2739-91.

44. Nishimura RA, Otto CM, Bonow RO, et al. 2017 AHA/ ACC Focused Update of the 2014 AHA/ACC Guideline for the Management of Patients With Valvular Heart Disease. J Am Coll Cardiol 2017;70:252-89.

45. Lytvyn L, Guyatt GH, Manja V, et al. Patient values and preferences on transcatheter or surgical aortic valve replacement therapy for aortic stenosis: a systematic review. BMJ Open 2016;6:e014327.

46. Indolfi C, Bartorelli AL, Berti S, et al. Updated clinical indications for transcatheter aortic valve implantation in patients with severe aortic stenosis. J Cardiovasc Med
(Hagerstown) 2018;19:197-210.

47. Siontis GCM, Jüni P, Pilgrim T, et al. Predictors of Permanent Pacemaker Implantation in Patients With Severe Aortic Stenosis Undergoing TAVR. J Am Coll Cardiol 2014;64:129-40.

48. Erkapic D, De Rosa S, Kelava A, Lehmann R, Fichtlscherer S, Hohnloser SH. Risk for permanent pacemaker after transcatheter aortic valve implantation: a comprehensive analysis of the literature. J Cardiovasc Electrophysiol 2012;23:391-7.

49. Khatri PJ, Webb JG, Rodés-Cabau J, et al. Adverse effects associated with transcatheter aortic valve implantation: a meta-analysis of contemporary studies. Ann Intern Med 2013;158:35-46.

50. Abdel-Wahab M, Mehilli J, Frerker C, et al. Comparison of Balloon-Expandable vs Self-expandable Valves in Patients Undergoing Transcatheter Aortic Valve Replacement. JAMA 2014;311:1503.

51. van Rosendael PJ, Delgado V, Bax JJ. Pacemaker implantation rate after transcatheter aortic valve implantation with early and new-generation devices: a systematic review. Eur Heart J 2018;39:2003-13.

52. Urena M, Webb JG, Tamburino C, et al. Permanent Pacemaker Implantation After Transcatheter Aortic Valve Implantation. Circulation 2014;129:1233-43.

53. Fadahunsi OO, Olowoyeye A, Ukaigwe A, et al. Incidence, Predictors, and Outcomes of Permanent Pacemaker Implantation Following Transcatheter Aortic Valve Replacement. JACC Cardiovasc Interv 2016;9:2189-99.

54. Toggweiler S, Kobza R. Pacemaker implantation after transcatheter aortic valve: why is this still happening? J Thorac Dis 2018;10:S3614-9.

55. Kodali S, Thourani VH, White J, et al. Early clinical and echocardiographic outcomes after SAPIEN 3 transcatheter aortic valve replacement in inoperable, high-risk and intermediate-risk patients with aortic stenosis. Eur Heart J 2016;37:2252-62.

56. Wendler O, Schymik G, Treede H, et al. SOURCE 3 Registry. Circulation 2017;135:1123-32.

57. Wendler O, Schymik G, Treede H, et al. SOURCE 3: 1-year outcomes post-transcatheter aortic valve implantation using the latest generation of the balloonexpandable transcatheter heart valve. Eur Heart J 2017;38:2717-26.

58. Pilgrim T, Stortecky S, Nietlispach F, et al. Repositionable Versus Balloon-Expandable Devices for Transcatheter Aortic Valve Implantation in Patients With Aortic Stenosis. J Am Heart Assoc 2016;5. doi: 10.1161/JAHA.116.004088. 
59. Manoharan G, Linke A, Moellmann H, et al. Multicentre clinical study evaluating a novel resheathable annular functioning self-expanding transcatheter aortic valve system: safety and performance results at 30 days with the Portico system. EuroIntervention 2016;12:768-74.

60. Manoharan G, Spence MS, Rodés-Cabau J, Webb JG. St Jude Medical Portico valve. EuroIntervention 2012;8 Suppl Q:Q97-101.

61. Linke A, Holzhey D, Möllmann H, et al. Treatment of Aortic Stenosis With a Self-Expanding, Resheathable Transcatheter Valve. Circ Cardiovasc Interv 2018;11:e005206.

62. Petronio AS, Sinning J-M, Van Mieghem N, et al. Optimal Implantation Depth and Adherence to Guidelines on Permanent Pacing to Improve the Results of Transcatheter Aortic Valve Replacement With the Medtronic CoreValve System. JACC Cardiovasc Interv 2015;8:837-46.

63. Popma JJ, Reardon MJ, Khabbaz K, et al. Early Clinical Outcomes After Transcatheter Aortic Valve Replacement Using a Novel Self-Expanding Bioprosthesis in Patients With Severe Aortic Stenosis Who Are Suboptimal for Surgery. JACC Cardiovasc Interv 2017;10:268-75.

64. Forrest JK, Mangi AA, Popma JJ, et al. Early Outcomes With the Evolut PRO Repositionable Self-Expanding Transcatheter Aortic Valve With Pericardial Wrap. JACC Cardiovasc Interv 2018;11:160-8.

65. Reichenspurner H, Schaefer A, Schäfer U, et al. SelfExpanding Transcatheter Aortic Valve System for Symptomatic High-Risk Patients With Severe Aortic Stenosis. J Am Coll Cardiol 2017;70:3127-36.

66. Husser O, Kim WK, Pellegrini C, et al. Multicenter Comparison of Novel Self-Expanding Versus BalloonExpandable Transcatheter Heart Valves. JACC Cardiovasc Interv 2017;10:2078-87.

67. Auffret V, Puri R, Urena M, et al. Conduction Disturbances After Transcatheter Aortic Valve Replacement: Current Status and Future Perspectives. Circulation 2017;136:1049-69.

68. Pereira E, Ferreira N, Caeiro D, et al. Transcatheter Aortic Valve Implantation and Requirements of Pacing Over Time. Pacing Clin Electrophysiol 2013;36:559-69.

69. Naveh S, Perlman GY, Elitsur Y, et al. Electrocardiographic Predictors of Long-Term Cardiac Pacing Dependency Following Transcatheter Aortic Valve Implantation. J Cardiovasc Electrophysiol 2017;28:216-23.

70. van der Boon RMA, Van Mieghem NM, Theuns DA, et al. Pacemaker dependency after transcatheter aortic valve implantation with the self-expanding Medtronic CoreValve
System. Int J Cardiol 2013;168:1269-73.

71. Alasti M, Rashid H, Rangasamy K, et al. Longterm pacemaker dependency and impact of pacing on mortality following transcatheter aortic valve replacement with the LOTUS valve. Catheter Cardiovasc Interv 2018;92:777-82.

72. Bob-Manuel T, Nanda A, Latham S, et al. Permanent pacemaker insertion in patients with conduction abnormalities post transcatheter aortic valve replacement: a review and proposed guidelines. Ann Transl Med 2018;6:11.

73. Rodés-Cabau J, Ellenbogen KA, Krahn AD, et al. Management of Conduction Disturbances Associated With Transcatheter Aortic Valve Replacement: JACC Scientific Expert Panel. J Am Coll Cardiol 2019;74:1086-106.

74. Van Belle E, Juthier F, Susen S, et al. Postprocedural Aortic Regurgitation in Balloon-Expandable and SelfExpandable Transcatheter Aortic Valve Replacement Procedures. Circulation 2014;129:1415-27.

75. Kodali S, Pibarot P, Douglas PS, et al. Paravalvular regurgitation after transcatheter aortic valve replacement with the Edwards sapien valve in the PARTNER trial: characterizing patients and impact on outcomes. Eur Heart J 2015;36:449-56.

76. Dworakowski R, Wendler O, Halliday B, et al. Device-dependent association between paravalvar aortic regurgitation and outcome after TAVI. Heart 2014;100:1939-45.

77. Athappan G, Patvardhan E, Tuzcu EM, et al. Incidence, predictors, and outcomes of aortic regurgitation after transcatheter aortic valve replacement: meta-analysis and systematic review of literature. J Am Coll Cardiol 2013;61:1585-95.

78. Mack MJ, Leon MB, Smith CR, et al. 5-year outcomes of transcatheter aortic valve replacement or surgical aortic valve replacement for high surgical risk patients with aortic stenosis (PARTNER 1): a randomised controlled trial. Lancet 2015;385:2477-84.

79. Kodali SK, Williams MR, Smith CR, et al. Two-year outcomes after transcatheter or surgical aortic-valve replacement. N Engl J Med 2012;366:1686-95.

80. Abdel-Wahab M, Abdelghani M, Miyazaki Y, et al. A Novel Angiographic Quantification of Aortic Regurgitation After TAVR Provides an Accurate Estimation of Regurgitation Fraction Derived From Cardiac Magnetic Resonance Imaging. JACC Cardiovasc Interv 2018;11:287-97.

81. Ong G, Annabi MS, Clavel MA, et al. Paravalvular Regurgitation After Transcatheter Aortic Valve 
Replacement: Is the Problem Solved? Interv Cardiol Clin 2018;7:445-58.

82. Bhatheja S, Panchal HB, Barry N, et al. Valvular performance and aortic regurgitation following transcatheter aortic valve replacement using Edwards valve versus CoreValve for severe aortic stenosis: A Metaanalysis. Cardiovasc Revasc Med 2016;17:248-55.

83. Thourani VH, Kodali S, Makkar RR, et al. Transcatheter aortic valve replacement versus surgical valve replacement in intermediate-risk patients: a propensity score analysis. Lancet 2016;387:2218-25.

84. Meredith Am IT, Walters DL, Dumonteil N, et al. Transcatheter aortic valve replacement for severe symptomatic aortic stenosis using a repositionable valve system: 30-day primary endpoint results from the REPRISE II study. J Am Coll Cardiol 2014;64:1339-48.

85. Pilgrim T, Lee JKT, O'Sullivan CJ, et al. Early versus newer generation devices for transcatheter aortic valve implantation in routine clinical practice: a propensity score matched analysis. Open Heart 2018;5:e000695.

86. Structural Heart Solutions I Abbott. Available online: https://www.structuralheartsolutions.com/. Accessed September 16, 2019.

87. Taramasso M, Denegri A, Kuwata S, et al. Feasibility and safety of transfemoral sheathless portico aortic valve implantation: Preliminary results in a single center experience. Catheter Cardiovasc Interv 2018;91:533-9.

88. Products - Boston Scientific. Available online: https:// www.bostonscientific.com/en-EU/products.html. Accessed September 16, 2019.

89. Kim WK, Hengstenberg C, Hilker M, et al. The SAVI-TF Registry: 1-Year Outcomes of the European Post-Market Registry Using the ACURATE neo Transcatheter Heart Valve Under Real-World Conditions in 1,000 Patients. JACC Cardiovasc Interv 2018;11:1368-74.

90. Zamorano J, Gonçalves A, Lancellotti P, et al. The use of imaging in new transcatheter interventions: an EACVI review paper. Eur Heart J Cardiovasc Imaging 2016;17:835-835af.

91. Husser O, Holzamer A, Resch M, et al. Prosthesis sizing for transcatheter aortic valve implantation - Comparison of three dimensional transesophageal echocardiography with multislice computed tomography. Int J Cardiol 2013;168:3431-8.

92. Van Belle E, Vincent F, Rauch A, et al. von Willebrand Factor and Management of Heart Valve Disease. J Am Coll Cardiol 2019;73:1078-88.

93. Van Belle E, Rauch A, Vincentelli A, et al. von Willebrand
Factor as a Biological Sensor of Blood Flow to Monitor Percutaneous Aortic Valve Interventions. Circ Res 2015;116:1193-201.

94. Van Belle E, Rauch A, Vincent F, et al. Von Willebrand Factor Multimers during Transcatheter Aortic-Valve Replacement. N Engl J Med 2016;375:335-44.

95. Kibler M, Marchandot B, Messas N, et al. CT-ADP Point-of-Care Assay Predicts 30-Day Paravalvular Aortic Regurgitation and Bleeding Events following Transcatheter Aortic Valve Replacement. Thromb Haemost 2018;118:893-905.

96. Nombela-Franco L, Rodés-Cabau J, DeLarochellière R, et al. Predictive Factors, Efficacy, and Safety of Balloon PostDilation After Transcatheter Aortic Valve Implantation With a Balloon-Expandable Valve. JACC Cardiovasc Interv 2012;5:499-512.

97. Sinning JM, Hammerstingl C, Vasa-Nicotera M, et al. Aortic Regurgitation Index Defines Severity of PeriProsthetic Regurgitation and Predicts Outcome in Patients After Transcatheter Aortic Valve Implantation. J Am Coll Cardiol 2012;59:1134-41.

98. Toggweiler S, Wood DA, Rodés-Cabau J, et al. Transcatheter Valve-In-Valve Implantation for Failed Balloon-Expandable Transcatheter Aortic Valves. JACC Cardiovasc Interv 2012;5:571-7.

99. Ussia GP, Barbanti M, Ramondo A, et al. The valvein-valve technique for treatment of aortic bioprosthesis malposition an analysis of incidence and 1-year clinical outcomes from the italian CoreValve registry. J Am Coll Cardiol 2011;57:1062-8.

100. Pibarot P, Hahn RT, Weissman NJ, et al. Association of Paravalvular Regurgitation With 1-Year Outcomes After Transcatheter Aortic Valve Replacement With the SAPIEN 3 Valve. JAMA Cardiol 2017;2:1208.

101. Oh JK, Little SH, Abdelmoneim SS, et al. Regression of Paravalvular Aortic Regurgitation and Remodeling of SelfExpanding Transcatheter Aortic Valve: An Observation From the CoreValve U.S. Pivotal Trial. JACC Cardiovasc Imaging 2015;8:1364-75.

102. Ghanem A, Müller A, Nähle CP, et al. Risk and Fate of Cerebral Embolism After Transfemoral Aortic Valve Implantation. J Am Coll Cardiol 2010;55:1427-32.

103. Kahlert P, Knipp SC, Schlamann M, et al. Silent and Apparent Cerebral Ischemia After Percutaneous Transfemoral Aortic Valve Implantation. Circulation 2010;121:870-8.

104.Daneault B, Kirtane AJ, Kodali SK, et al. Stroke Associated With Surgical and Transcatheter Treatment of Aortic 
Stenosis. J Am Coll Cardiol 2011;58:2143-50.

105. Pagnesi M, Martino EA, Chiarito M, et al. Silent cerebral injury after transcatheter aortic valve implantation and the preventive role of embolic protection devices: A systematic review and meta-analysis. Int J Cardiol 2016;221:97-106.

106. Athappan G, Gajulapalli RD, Sengodan P, et al. Influence of transcatheter aortic valve replacement strategy and valve design on stroke after transcatheter aortic valve replacement: a meta-analysis and systematic review of literature. J Am Coll Cardiol 2014;63:2101-10.

107. Werner N, Zeymer U, Schneider S, et al. Incidence and Clinical Impact of Stroke Complicating Transcatheter Aortic Valve Implantation: Results From the German TAVIRegistry. Catheter Cardiovasc Interv 2016;88:644-53.

108. Nombela-Franco L, Armijo G, Tirado-Conte G. Cerebral embolic protection devices during transcatheter aortic valve implantation: clinical versus silent embolism. J Thorac Dis 2018;10:S3604-13.

109. Bagur R, Solo K, Alghofaili S, et al. Cerebral Embolic Protection Devices During Transcatheter Aortic Valve Implantation: Systematic Review and Meta-Analysis. Stroke 2017;48:1306-15.

110. Testa L, Latib A, Casenghi M, et al. Cerebral Protection During Transcatheter Aortic Valve Implantation: An Updated Systematic Review and Meta-Analysis. J Am Heart Assoc 2018;7. doi: 10.1161/JAHA.117.008463.

111. Seeger J, Gonska B, Otto M, Rottbauer W, Wöhrle J. Cerebral Embolic Protection During Transcatheter Aortic Valve Replacement Significantly Reduces Death and Stroke Compared With Unprotected Procedures. JACC Cardiovasc Interv 2017;10:2297-303.

112. Kapadia SR, Kodali S, Makkar R, et al. Protection Against Cerebral Embolism During Transcatheter Aortic Valve Replacement. J Am Coll Cardiol 2017;69:367-77.

113. Goel SS, Ige M, Tuzcu EM, et al. Severe aortic stenosis and coronary artery disease--implications for management in the transcatheter aortic valve replacement era: a comprehensive review. J Am Coll Cardiol 2013;62:1-10.

114. Baron SJ, Arnold SV, Herrmann HC, et al. Impact of Ejection Fraction and Aortic Valve Gradient on Outcomes of Transcatheter Aortic Valve Replacement. J Am Coll Cardiol 2016;67:2349-58.

115. Walther T, Hamm CW, Schuler G, et al. Perioperative Results and Complications in 15,964 Transcatheter Aortic Valve Replacements. J Am Coll Cardiol 2015;65:2173-80.

116. D'Ascenzo F, Conrotto F, Giordana F, et al. Mid-term prognostic value of coronary artery disease in patients undergoing transcatheter aortic valve implantation: A meta-analysis of adjusted observational results. Int J Cardiol 2013;168:2528-32.

117. Sankaramangalam K, Banerjee K, Kandregula K, et al. Impact of Coronary Artery Disease on 30 Day and 1 Year Mortality in Patients Undergoing Transcatheter Aortic Valve Replacement: A Meta Analysis. J Am Heart Assoc 2017;6. doi: 10.1161/JAHA.117.006092.

118. Witberg G, Zusman O, Codner P, Assali A, Kornowski R. Impact of Coronary Artery Revascularization Completeness on Outcomes of Patients With Coronary Artery Disease Undergoing Transcatheter Aortic Valve Replacement. Circ Cardiovasc Interv 2018;11:e006000.

119. Khawaja MZ, Wang D, Pocock S, Redwood SR, Thomas MR. The percutaneous coronary intervention prior to transcatheter aortic valve implantation (ACTIVATION) trial: study protocol for a randomized controlled trial. Trials 2014;15:300.

120. Yudi MB, Sharma SK, Tang GHL, Kini A. Coronary Angiography and Percutaneous Coronary Intervention After Transcatheter Aortic Valve Replacement. J Am Coll Cardiol 2018;71:1360-78.

121. Une D, Ruel M, David TE. Twenty-year durability of the aortic Hancock II bioprosthesis in young patients: is it durable enough?†. Eur J Cardiothorac Surg 2014;46:825-30.

122.Durand E, Sokoloff A, Urena-Alcazar M, et al. Assessment of Long-Term Structural Deterioration of Transcatheter Aortic Bioprosthetic Valves Using the New European Definition. Circ Cardiovasc Interv 2019;12:e007597.

123. Rodriguez-Gabella T, Voisine P, Puri R, Pibarot P, RodésCabau J. Aortic Bioprosthetic Valve Durability. J Am Coll Cardiol 2017;70:1013-28.

124.Lancellotti P, Martinez C, Radermecker M. The Long Quest for the Holy Grail in Transcatheter Aortic Bioprosthesis: Durability and Long-Term Performance. J Am Coll Cardiol 2019;73:554-8.

125. Martinez C, Gach O, Radermecker MA, et al. Transcatheter aortic valve replacement : from a concept to a medical revolution. Rev Med Liege 2019;74:S64-72.

126. Deeb GM, Reardon MJ, Chetcuti S, et al. 3-Year Outcomes in High-Risk Patients Who Underwent Surgical or Transcatheter Aortic Valve Replacement. J Am Coll Cardiol 2016;67:2565-74.

127. Toggweiler S, Humphries KH, Lee M, et al. 5-year outcome after transcatheter aortic valve implantation. J Am Coll Cardiol 2013;61:413-9.

128. Blackman DJ, Saraf S, MacCarthy PA, et al. Long-Term Durability of Transcatheter Aortic Valve Prostheses. J Am 
Coll Cardiol 2019;73:537-45.

129. Capodanno D, Petronio AS, Prendergast B, et al.

Standardized definitions of structural deterioration and valve failure in assessing long-term durability of transcatheter and surgical aortic bioprosthetic valves: a consensus statement from the European Association of Percutaneous Cardiovascular Interventions (EAPCI) endorsed by the European Society of Cardiology (ESC) and the European Association for Cardio-Thoracic Surgery (EACTS). Eur Heart J 2017;38:3382-90.

130. Barbanti M, Costa G, Zappulla P, et al. Incidence of Long Term Structural Valve Dysfunction and Bioprosthetic Valve Failure After Transcatheter Aortic Valve Replacement. J Am Heart Assoc 2018;7:e008440.

131. Søndergaard L, Ihlemann N, Capodanno D, et al. Durability of Transcatheter and Surgical Bioprosthetic Aortic Valves in Patients at Lower Surgical Risk. J Am Coll Cardiol 2019;73:546-53.

132.Panico RA, Giannini C, De Carlo M, et al. Long-term

Cite this article as: Mas-Peiro S, Fichtlscherer S, Walther C, Vasa-Nicotera M. Current issues in transcatheter aortic valve replacement. J Thorac Dis 2020;12(4):1665-1680. doi: 10.21037/ jtd.2020.01.10 results and durability of the CoreValve transcatheter aortic bioprosthesis: outcomes beyond five years. EuroIntervention 2019;14:1639-47.

133. Holy EW, Kebernik J, Abdelghani M, et al. Long-term durability and haemodynamic performance of a selfexpanding transcatheter heart valve beyond five years after implantation: a prospective observational study applying the standardised definitions of structural deterioration and valve failure. EuroIntervention 2018;14:e390-6.

134.Eltchaninoff H, Durand E, Avinée G, et al. Assessment of structural valve deterioration of transcatheter aortic bioprosthetic balloon-expandable valves using the new European consensus definition. EuroIntervention 2018;14:e264-71.

135.Deutsch MA, Erlebach M, Burri M, et al. Beyond the five-year horizon: long-term outcome of high-risk and inoperable patients undergoing TAVR with firstgeneration devices. EuroIntervention 2018;14:41-9. 